\title{
Association of direct bilirubin level with postoperative outcome in critically ill postoperative patients
}

\author{
Masaharu Nagae, Moritoki Egi, Kenta Kubota, Shohei Makino, and \\ Satoshi Mizobuchi
}

Department of Anesthesiology, Kobe University Hospital, Kobe, Japan

\begin{abstract}
Background: Hyperbilirubinemia is a common postoperative complication. Elevated direct bilirubin (D-Bil) and indirect bilirubin (I-Bil) levels are related to different pathophysiologies; therefore, their associations with outcomes also differ. However, there have been few comparative studies of such associations in postoperative patients.

Methods: This retrospective study compared the associations of postoperative D-Bil and I-Bil with outcomes. We included adult patients requiring postoperative intensive care for more than 48 hours between 2008 and 2013, except those undergoing liver operations. The number of patients was determined using a power calculation. D-Bil and I-Bil measurements were obtained on postoperative days (POD) 1 and 2 . The primary outcome was defined as hospital mortality, with the number of ICU-free survival days (IFSD) at POD 28 as the secondary outcome.

Results: The study population consisted of 1,903 patients with a mortality rate of $2.2 \%$. D-Bil at POD 1 was significantly higher in non-survivors than survivors $(P=0.001)$, but $I-B i l$ at $P O D 1$ showed no such relation $(P=0.209)$. Multivariate logistic analysis indicated that higher postoperative $\mathrm{D}$-Bil was independently associated with increased postoperative mortality (POD 1: adjusted odds ratio $[\mathrm{OR}]=2.32, \mathrm{P}<0.001$; $\mathrm{POD} 2$ : adjusted $\mathrm{OR}=1.95, \mathrm{P}<0.001$ ), but I-Bil showed no such relation (POD 1: $\mathrm{P}=0.913$; POD 2: $\mathrm{P}=0.209$ ). Increased $\mathrm{D}-\mathrm{Bil}$ was independently associated with decreased IFSD at POD 28 (POD 1: adjusted coefficient $=-1.54, \mathrm{P}<0.001$; POD 2: $-1.84, \mathrm{P}<0.001$ ). In contrast, increased I-Bil at POD 1 was independently associated with increased IFSD at POD 28 (POD 1: adjusted coefficient $=+0.39, \mathrm{P}=0.021$; POD 2: $+0.33, \mathrm{P}=0.080$ ).
\end{abstract}

Conclusions: D-Bil indices have a higher capability than I-Bil for predicting poorer outcomes in critically ill postoperative patients.

Keywords: Bilirubin; Critical ill; Direct; Indirect; Postoperative.

Corresponding author: Moritoki Egi, M.D.

Department of Anesthesiology, Kobe University Hospital, 7-5-2, Kusunoki cho, Chuo-ku, Kobe, Hyogo 650-0017, Japan

Tel: 81-78-382-6172, Fax: 81-78-382-6189

Email: moriori@tg8.so-net.ne.jp

ORCID: https://orcid.org/0000-0002-0099-3060

Received: April 24, 2017.

Revised: August 7, 2017 (1st); August 28, 2017 (2nd).

Accepted: August 31, 2017.

Korean J Anesthesiol 2018 February 71(1): 30-36

https://doi.org/10.4097/kjae.2018.71.1.30

\section{Introduction}

Postoperative hyperbilirubinemia occurs frequently following surgery and is associated with a poor outcome [1]. Total bilirubin consists of direct bilirubin (D-Bil) and indirect bilirubin (I-Bil). Increased D-Bil is associated with hepatocyte excretory dysfunction, including hypoxic hepatocyte injury, sepsis-associated cholestasis, and drug-induced liver injury [2]. In contrast, increased I-Bil is related to various other conditions, including hemolysis and blood transfusion reaction [3]. These different pathophysiologies suggest that D-Bil and I-Bil may have different associations with clinical outcome $[4,5]$.

(c) This is an open-access article distributed under the terms of the Creative Commons Attribution Non-Commercial License (http://creativecommons.org/ licenses/by-nc/4.0/), which permits unrestricted non-commercial use, distribution, and reproduction in any medium, provided the original work is properly cited. 
Postoperative organ dysfunction is a significant outcome in patients requiring surgery, and anesthesiologists should therefore take steps to prevent and treat this. Definitions of different types of acute organ dysfunction have been proposed and are widely used, including postoperative acute kidney injury [6], acute respiratory dysfunction [7], and delirium [8]. A number of interventional studies have been conducted regarding the prevention and treatment of these clearly defined types of acute organ dysfunction. However, there is still no clear definition of postoperative liver dysfunction. Bilirubin level has been considered as a surrogate marker of liver dysfunction. However, there have been few studies regarding the associations of postoperative D-Bil and I-Bil with outcome. Therefore, we conducted a retrospective study to compare the associations of postoperative D-Bil and IBil with outcomes in postoperative critically ill patients.

\section{Materials and Methods}

This was a single-center retrospective observational study comparing the associations between $\mathrm{D}$-Bil and I-Bil measured at postoperative days (POD) 1 and 2 and clinical outcomes in postoperative critically ill patients. The Kobe University Hospital Ethics Committee approved this study and waived the need for informed consent for studies involving the use of the database. The study was performed in accordance with the principles outlined in the Declaration of Helsinki.

\section{Participants and patient characteristics}

We screened all adult patients that underwent surgery under general anesthesia at our institution between 2008 and 2013. Our inclusion criterion was the requirement for postoperative intensive care for more than 48 hours. To eliminate the confounding effect of higher preoperative bilirubin levels, we excluded patients with preoperative T-Bil level $>1 \mathrm{mg} / \mathrm{dl}$, as this is considered the upper normal limit at our institution. We also excluded patients undergoing hepatic surgery and those with an American Society of Anesthesiologists-Physical Status (ASAPS) score $\geq 5$. Patient characteristics, including age, sex, ASA-PS score, length of intensive care unit (ICU) stay, length of hospital stay, elective or emergency surgery, and type of surgery, were obtained. Preoperative T-Bil and hepatic enzyme levels [alanine transaminase (ALT) and aspartate transaminase (AST)] were obtained. We also obtained the Acute Physiology and Chronic Health Evaluation (APACHE) II score for patients in whom reliable information was available for its calculation.

\section{Measurement of postoperative bilirubin levels}

We obtained D-Bil and I-Bil levels measured at 06:00 on
PODs 1 and 2. D-Bil and I-Bil levels at our institution are measured by enzymatic assay of bilirubin oxidase (IATRO T-BIL ${ }^{\mathrm{TM}}$ and IATRO D-BIL ${ }^{\mathrm{TM}}$, respectively; LSI Medience Corp., Tokyo, Japan). The normal ranges of D-Bil and I-Bil are $\leq 0.2 \mathrm{mg} / \mathrm{dl}$ and $\leq 0.7 \mathrm{mg} / \mathrm{dl}$, respectively.

\section{Outcomes}

The primary outcome was defined as postoperative hospital mortality, with the number of ICU-free survival days (IFSD) at POD 28 as the secondary outcome. Discharge from ICU was at the discretion of the attending physician when the patient's physiological status had stabilized and the patient was free from the following: 1) the requirement for mechanical ventilation or risk of reintubation; 2) hemodynamic instability; and 3) the requirement for renal replacement therapy.

We obtained information on the proximate cause of death. In accordance with a previous study [9], we used five cause-ofdeath categories: (1) neurological (traumatic and nontraumatic brain injury, both with and without brain death); (2) cardiovascular (arrhythmia, cardiogenic shock, distributive [septic] shock, and hypovolemic shock); (3) respiratory (hypoxic respiratory failure); (4) liver-related (liver failure); and (5) other.

\section{Statistical analysis}

Data are presented as percentages (n/valid cases) or as the median (25\% quartile, $75 \%$ quartile). Comparisons between two groups were performed using the Mann-Whitney $U$ test and chi-square test.

For primary comparisons, we compared D-Bil and I-Bil levels at PODs 1 and 2 between survivors and non-survivors. To calculate the sample size for the present study, we considered a difference of $40 \%$ in the standard deviation for D-Bil and I-Bil levels to be meaningful. Assuming a postoperative hospital mortality rate of $2.5 \%$, a power of 0.90 , and an a level of 0.05 , approximately 1,900 participants were required. As approximately $13 \%$ of adult postoperative patients require postoperative intensive care for more than 48 hours, and $40 \%$ of patients were at risk of exclusion according to our exclusion criteria, we planned to screen approximately 23,000 adult postoperative patients. As the study site performed 4,000 operations requiring general anesthesia per year, and a reliable dataset was available before 2013, the study period was set from 2008 to 2013.

To confirm the independent associations between $\mathrm{D}$-Bil and I-Bil levels and mortality, we performed multivariate logistic analysis using postoperative mortality as a dependent variable, and age, ASA-PS, operation category, emergency operation, DBil, and I-Bil levels as independent variables. Adjusted odds ratios (ORs) are presented with 95\% CI. 
As the relationship between postoperative bilirubin level and outcome may not be linear, we further subdivided patients according to the upper limits of the bilirubin level and compared outcomes among the following subgroups: Normal, within the normal range (D-Bil $\leq 0.2 \mathrm{mg} / \mathrm{dl}$, $\mathrm{I}-\mathrm{Bil} \leq 0.7 \mathrm{mg} / \mathrm{dl}$ ); Mild hyper D-Bil or I-Bil, $1^{\star}$ upper limit-2*upper limit $(0.2 \mathrm{mg} / \mathrm{dl}<\mathrm{D}$-Bil $\leq$ $0.4 \mathrm{mg} / \mathrm{dl}, 0.7 \mathrm{mg} / \mathrm{dl}<\mathrm{I}-\mathrm{Bil} \leq 1.4 \mathrm{mg} / \mathrm{dl})$; and Moderate hyper D-Bil or I-Bil, $>2^{*}$ upper limit $(0.4 \mathrm{mg} / \mathrm{dl}<\mathrm{D}-$ Bil, $1.4 \mathrm{mg} / \mathrm{dl}<$ I-Bil). We also performed a multivariate logistic analysis of hospital mortality using mild and moderate hyper D-Bil or I-Bil as dependent variables, and a multivariate linear regression analysis using IFSD at POD 28 days as the dependent variable.

Statistical analyses were performed using R software (ver. 3.2.2; R Development Core Team, Vienna, Austria). In all analyses, $\mathrm{P}<0.05$ was taken to indicate statistical significance. Data are reported in accordance with the Strengthening the Reporting of Observational Studies in Epidemiology (STROBE) guidelines.

\section{Results}

\section{Study flow}

A total of 23,676 adult patients underwent surgery under general anesthesia during the study period. Among them, 3,431 patients remained in the ICU for more than 48 hours. Patients

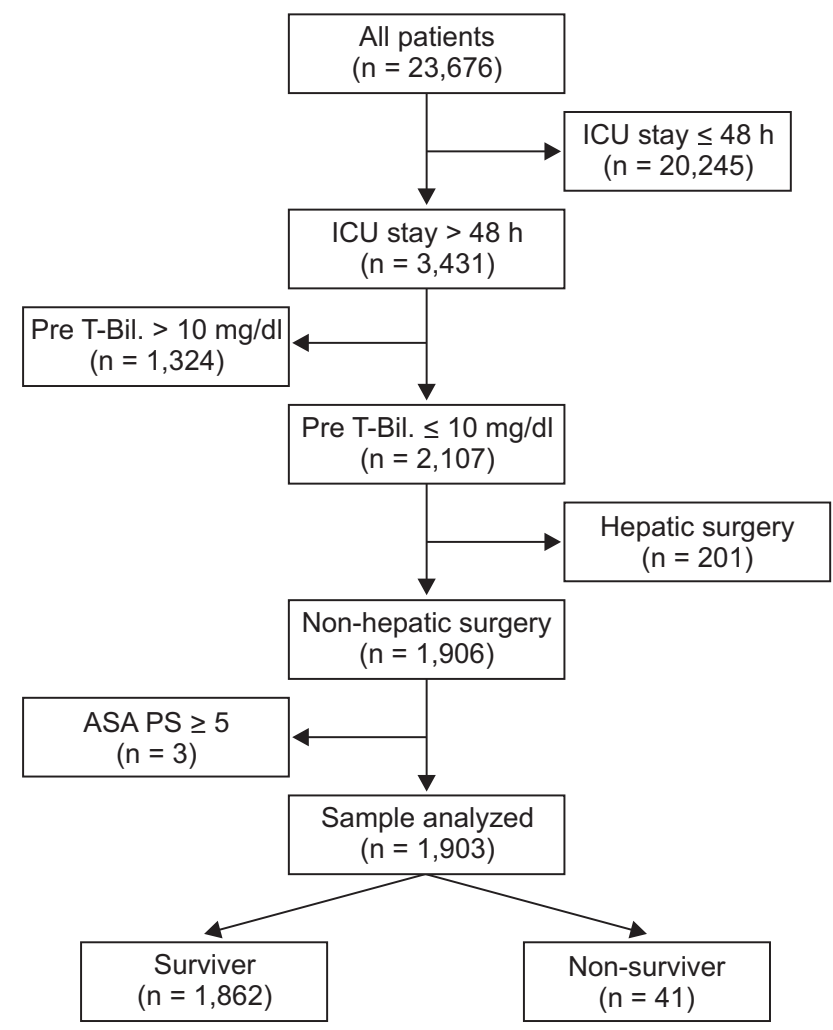

Fig. 1. Study flow. with a preoperative T-Bil level $>1 \mathrm{mg} / \mathrm{dl}(\mathrm{n}=1,324)$, those undergoing hepatic surgery $(n=201)$, and patients with an ASA-PS $\geq 5$ were excluded. The remaining 1,903 patients were included in the study (Fig. 1).

\section{Possible confounders}

Among the 1,903 patients included in the study, 41 did not survive (mortality $=2.2 \%$ ). Table 1 shows the proximate cause of death in non-survivors. Table 2 shows a comparison of patient characteristics between survivors and non-survivors. Non-survivors had significantly higher ASA-PS scores and a greater likelihood of emergency surgery compared with survivors. There was no significant difference in age, gender, or operation site between the two groups. The preoperative T-Bil level in nonsurvivors had a median value of $0.6(0.4,0.7) \mathrm{mg} / \mathrm{dl}$, which was not significantly different from the value of $0.6(0.4,0.7) \mathrm{mg} / \mathrm{dl}$ observed in survivors $(\mathrm{P}=0.481)$. Preoperative AST and ALT levels were not significantly different between non-survivors and survivors (AST, $19[15,25]$ vs. $20[14,30]$ unit/l, $\mathrm{P}=0.731$; ALT, $15[10,24]$ vs. $15[8,25]$ unit/l, $\mathrm{P}=0.799)$. The APACHE II score was obtained in 1,072 of 1,903 patients, including 1,031 patients among the 1,862 survivors (55.4\%) and all 41 of the 41 non-survivors (100\%). The APACHE II score was significantly higher in non-survivors than survivors $(\mathrm{P}=0.009)$.

\section{Comparison of D-Bil and I-Bil levels between survivors and non-survivors}

Table 3 shows a comparison of the D-Bil and I-Bil levels between survivors and non-survivors. D-Bil at POD 1 in non-survivors was significantly higher than in survivors $(\mathrm{P}=0.001)$, but no such relation was observed for I-Bil at POD $1(\mathrm{P}=0.209)$. D-Bil and I-Bil at POD 2 were significantly higher in non-survivors than survivors (D-Bi: $\mathrm{P}<0.001$, I-Bil: $\mathrm{P}=0.013$ ).

After adjusting for predefined confounders in multivariate logistic analysis, we found that a higher D-Bil was independently associated with an increase in postoperative mortality (POD 1 : adjusted $\mathrm{OR}=2.32(1.61,3.34), \mathrm{P}<0.001$; POD 2: $1.95(1.45$, $2.62), \mathrm{P}<0.001)$, but no such relation was observed for I-Bil (POD 1: $\mathrm{P}=0.913$; POD 2: $\mathrm{P}=0.209$ ) (Table 4). These results

Table 1. Proximate Causes of Death in 41 Non-survivors

\begin{tabular}{lc}
\hline Proximate cause of death & $\mathrm{n}(\%)$ \\
\hline Neurological & $4(9.8 \%)$ \\
Cardiovascular & $12(29.3 \%)$ \\
Respiratory & $20(48.8 \%)$ \\
Liver failure & $3(7.3 \%)$ \\
Other & $2(4.9 \%)$ \\
\hline
\end{tabular}


Table 2. Comparison between Postoperative Survivors and Non-survivors

\begin{tabular}{|c|c|c|c|c|}
\hline Characteristics & Survivors $(\mathrm{n}=1,862)$ & Non-survivors $(\mathrm{n}=41)$ & $P$ value & All $(\mathrm{n}=1,903)$ \\
\hline Age (y.o.) & $68(59,75)$ & $71(66,78)$ & 0.074 & $68(59,76)$ \\
\hline Male (\%) & $1,181(63.4 \%)$ & $28(68.3 \%)$ & 0.634 & $1,209(63.5 \%)$ \\
\hline ASA-PS & $2(2,3)$ & $3(2,3)$ & $<0.001$ & $2(2,3)$ \\
\hline APACHE II score* & $16(15,19)$ & $18(13,25)$ & 0.009 & $16(12,19)$ \\
\hline ICU stay (day) & $4(3,5)$ & $16(5,26)$ & $<0.001$ & $4(3,5)$ \\
\hline Postoperative hospital stay (day) & $33(24,52)$ & $64(33,137)$ & $<0.001$ & $33(24,53)$ \\
\hline Emergency surgery (\%) & $232(12.5 \%)$ & $14(34.1 \%)$ & $<0.001$ & $246(13.1 \%)$ \\
\hline \multicolumn{5}{|l|}{ Categories of surgery } \\
\hline Cardiovascular (\%) & $910(48.9 \%)$ & $16(39.0)$ & 0.276 & $926(48.7)$ \\
\hline Digestive tract (\%) & $276(14.8 \%)$ & $10(24.4)$ & 0.140 & $286(15.0)$ \\
\hline Head and neck (\%) & $212(11.4 \%)$ & $5(12.2)$ & 0.804 & $217(11.4)$ \\
\hline Urology $(\%)$ & $128(6.9 \%)$ & $3(7.3)$ & 0.758 & $131(6.9)$ \\
\hline Pancreatic (\%) & $115(6.2 \%)$ & $0(0)$ & 0.173 & $115(6.0)$ \\
\hline Neurosurgery (\%) & $104(5.6 \%)$ & $5(12.2 \%)$ & 0.081 & $109(5.7)$ \\
\hline Others $(\%)$ & $117(6.3 \%)$ & $2(4.9 \%)$ & 0.967 & $119(6.3)$ \\
\hline
\end{tabular}

Data are presented as percentages (n/valid cases) or as the median (25\% quartile, $75 \%$ quartile). Comparisons between two groups were performed using the Mann-Whitney $U$ test and chi-square test. ASA-PS: American Society of Anesthesiologists-physical status, ICU: intensive care unit, APACHE: acute physiology and chronic health evaluation. *APACHE II score was obtained in 1,072 of 1,903 patients, including 1,031 of 1,862 survivors (55.4\%) and all of 41 non-survivors (100\%).

Table 3. Comparison of Bilirubin Level between Postoperative Survivors and Non-survivors

\begin{tabular}{cclcr}
\hline Day & $\begin{array}{c}\text { Bilirubin } \\
\text { subtypes }\end{array}$ & $\begin{array}{c}\text { Survivors } \\
(\mathrm{mg} / \mathrm{dl})\end{array}$ & $\begin{array}{c}\text { Non-survivors } \\
(\mathrm{mg} / \mathrm{dl})\end{array}$ & P value \\
\hline POD 1 & D-Bil & $0.1(0,0.2)$ & $0.2(0,0.7)$ & 0.001 \\
& I-Bil & $0.8(0.6,1.2)$ & $1(0.7,1.4)$ & 0.209 \\
POD 2 & D-Bil & $0.1(0,0.2)$ & $0.2(0.1,1.0)$ & $<0.001$ \\
& I-Bil & $0.7(0.5,1.0)$ & $0.8(0.6,1.3)$ & 0.013 \\
\hline
\end{tabular}

Data are presented as the median (25\% quartile, $75 \%$ quartile). Comparisons between two groups were performed using the Mann-Whitney $U$ test. POD: postoperative day, D-Bil: direct bilirubin, I-Bil: indirect bilirubin.

did not change even after adjusting for the APACHE II score.

We also performed a categorical analysis. At POD 1, mild increases in D-Bil and I-Bil levels were observed in 175 (9.2\%) and $839(44.1 \%)$ patients, respectively. Moderate increases in D-Bil and I-Bil levels at POD 1 were seen in 202 (10.6\%) and 287 (15.1\%) patients, respectively. The numbers of patients with mild or moderate hyper D-Bil and I-Bil decreased at POD 2 (D-Bil: mild, $\mathrm{n}=136$ [7.1\%]; moderate, $\mathrm{n}=143$ [7.5\%]; I-Bil: mild, $\mathrm{n}=676$ [35.5\%]; moderate, $\mathrm{n}=134$ [7.0\%]). Table 5 shows the adjusted ORs of mild and moderate hyper D-Bil and I-Bil for postoperative mortality. Mild and moderate increases in D-Bil levels were independently associated with increased postoperative mortality compared to D-Bil levels within the normal range (Mild at POD 1: adjusted OR = $2.62[1.00,6.84], \mathrm{P}=0.049$; Mild at POD 2: $3.25[1.23,8.56], \mathrm{P}=0.017$; Moderate at POD 1: 3.86 $[1.70,8.74], \mathrm{P}=0.001$; Moderate at POD 2: $4.53[1.92,10.7], \mathrm{P}<$ 0.001), but no such relations were observed for I-Bil (Mild: POD
$1, \mathrm{P}=0.986 ;$ POD 2, $\mathrm{P}=0.251$; Moderate: POD 1, $\mathrm{P}=0.729$; POD 2, $\mathrm{P}=0.137)$.

We further performed a multivariate linear regression analysis using IFSD as the dependent variable. The increase in D-Bil level was independently associated with decreased IFSD (POD 1: adjusted coefficient $=-1.54, \mathrm{P}<0.001 ; \mathrm{POD} 2:-1.84, \mathrm{P}<0.001)$. In contrast, the increase in I-Bil at POD 1 was independently associated with increased IFSD (adjusted coefficient $=0.39, \mathrm{P}=$ 0.021) (Table 6).

\section{Discussion}

\section{Key findings}

In this retrospective observational study comparing the associations between D-Bil and I-Bil levels and postoperative outcomes, we found that the D-Bil level had a more robust association with poorer outcomes (increased postoperative mortality and decreased IFSD) than I-Bil. This study is novel as there have been no previous reports regarding the associations between increases in D-Bil and I-Bil levels in the early postoperative period and postoperative outcomes.

\section{Comparison with previous studies}

In the critical care setting, there have been few studies comparing the associations of D-Bil and I-Bil levels with outcomes. Pineda et al. [5] performed a prospective observational study to assess the associations of total and D-Bil levels with the clinical 
Table 4. Multivariate Analysis of the Association between Postoperative Bilirubin Level and Postoperative Mortality

\begin{tabular}{|c|c|c|c|}
\hline & Independent variable & Bilirubin subtypes & Adjusted odds ratio $(95 \% \mathrm{CI})$ \\
\hline \multirow{8}{*}{$\begin{array}{l}\text { Independent association of } \\
\text { bilirubin level at POD } 1 \\
\text { with mortality }\end{array}$} & \multirow[t]{2}{*}{ D-Bil and I-Bil } & D-Bil & $\begin{array}{l}2.52(1.79,3.54) \\
\mathrm{P}<0.001\end{array}$ \\
\hline & & I-Bil & $\begin{array}{l}0.89(0.50,1.58) \\
P=0.690\end{array}$ \\
\hline & \multirow{2}{*}{$\begin{array}{l}\text { D-Bil, I-Bil, } \\
\text { age, ASA-PS, and } \\
\text { operation category }\end{array}$} & D-Bil & $\begin{array}{l}2.40(1.68,3.43) \\
\mathrm{P}<0.001\end{array}$ \\
\hline & & I-Bil & $\begin{array}{l}0.94(0.54,1.64) \\
P=0.824\end{array}$ \\
\hline & \multirow{2}{*}{$\begin{array}{l}\text { D-Bil, I-Bil, } \\
\text { age, ASA-PS, operation category, } \\
\text { and emergency operation }\end{array}$} & D-Bil & $\begin{array}{l}2.32(1.61,3.34) \\
\mathrm{P}<0.001\end{array}$ \\
\hline & & I-Bil & $\begin{array}{l}0.97(0.55,1.71) \\
P=0.913\end{array}$ \\
\hline & \multirow{2}{*}{$\begin{array}{l}\text { D-Bil, I-Bil, } \\
\text { age, ASA-PS, operation category, } \\
\text { emergency operation, and } \\
\text { APACHE II score* }\end{array}$} & D-Bil & $\begin{array}{l}2.46(1.61,3.74) \\
\mathrm{P}<0.001\end{array}$ \\
\hline & & I-Bil & $\begin{array}{l}0.89(0.50,1.60) \\
P=0.698\end{array}$ \\
\hline \multirow{8}{*}{$\begin{array}{l}\text { Independent association of } \\
\text { bilirubin level at POD } 2 \\
\text { with mortality }\end{array}$} & \multirow[t]{2}{*}{ D-Bil and I-Bil } & D-Bil & $\begin{array}{l}2.03(1.53,2.69) \\
P<0.001\end{array}$ \\
\hline & & I-Bil & $\begin{array}{l}1.31(0.81,2.13) \\
\mathrm{P}=0.275\end{array}$ \\
\hline & \multirow{2}{*}{$\begin{array}{l}\text { D-Bil, I-Bil, } \\
\text { age, ASA-PS, and } \\
\text { operation category }\end{array}$} & D-Bil & $\begin{array}{l}1.97(1.47,2.63) \\
P<0.001\end{array}$ \\
\hline & & I-Bil & $\begin{array}{l}1.29(0.82,2.03) \\
P=0.266\end{array}$ \\
\hline & \multirow{2}{*}{$\begin{array}{l}\text { D-Bil, I-Bil, } \\
\text { age, ASA-PS, operation category, } \\
\text { and emergency operation }\end{array}$} & D-Bil & $\begin{array}{l}1.95(1.45,2.62) \\
P<0.001\end{array}$ \\
\hline & & I-Bil & $\begin{array}{l}1.34(0.85,2.12) \\
P=0.209\end{array}$ \\
\hline & \multirow{2}{*}{$\begin{array}{l}\text { D-Bil, I-Bil, } \\
\text { age, ASA-PS, operation category, } \\
\text { emergency operation, and } \\
\text { APACHE II score* }\end{array}$} & D-Bil & $\begin{array}{l}2.10(1.45,3.04) \\
P<0.001\end{array}$ \\
\hline & & I-Bil & $\begin{array}{l}1.28(0.74,2.24) \\
P=0.382\end{array}$ \\
\hline
\end{tabular}

POD: postoperative day, D-Bil: direct bilirubin, I-Bil: indirect bilirubin, ASA-PS: American Society of Anesthesiologists-physical status, CI: confidence interval. *APACHE II score was obtained in 1,072 of 1,903 patients, including 1,031 of 1,862 survivors (55.4\%) and all of 41 non-survivors (100\%).

Table 5. Associations between Mild and Moderate Hyperbilirubinemia and Postoperative Mortality

\begin{tabular}{lccc}
\hline & Bilirubin subtype & $\begin{array}{c}\text { Mild hyperbilirubinemia } \\
\text { (vs. normal bilirubin levels) } \\
\text { Adjusted odds ratio (95\% CI) }\end{array}$ & $\begin{array}{c}\text { Moderate hyperbilirubinemia } \\
\text { (vs. normal bilirubin levels) } \\
\text { Adjusted odds ratio (95\% CI) }\end{array}$ \\
\hline $\begin{array}{l}\text { Hyperbilirubinemia at POD 1 } \\
\text { for mortality }\end{array}$ & D-Bil & $2.62(1.00,6.84)$ & $3.86(1.70,8.74)$ \\
& I-Bil & $\mathrm{P}=0.049$ & 1.001 \\
& & $1.01(0.47,2.16)$ & $\mathrm{P}=0.729$ \\
Hyperbilirubinemia at POD 2 & D-Bil & $\mathrm{P}=0.986$ & $4.53(1.92,10.7)$ \\
for mortality & I-Bil & $3.25(1.23,8.56)$ & $\mathrm{P}<0.001$ \\
& & $\mathrm{P}=0.017$ & $2.22(0.78,6.36)$ \\
\end{tabular}

Multivariate logistic analysis was performed using hyperbilirubinemia of D-Bil and I-Bil, age, ASA-PS, operation category, and emergency operation as dependent variables, and mortality as the independent variable. POD: postoperative day, D-Bil: direct bilirubin, I-Bil: indirect bilirubin, ASA-PS: American Society of Anesthesiologists-physical status.

presentation and outcomes in 743 patients hospitalized with ischemic stroke. They concluded that a higher D-Bil level was associated with greater stroke severity. Wu et al. [4] performed a prospective observational study to assess the associations between D-Bil and I-Bil levels and mortality in 162 patients with enteric fistula-related abdominal sepsis. They reported that the 
Table 6. Association between Postoperative Direct and Indirect Bilirubin Levels and ICU-free Survival Days at 28 Days after the Operation

\begin{tabular}{lcl}
\hline & Bilirubin subtype & $\begin{array}{c}\text { Coefficient } \\
\text { P value }\end{array}$ \\
\hline $\begin{array}{l}\text { Independent association } \\
\text { of bilirubin level at }\end{array}$ & D-Bil & -1.54 \\
POD 1 and IFSD & I-Bil & $\mathrm{P}<0.001$ \\
& & 0.39 \\
$\begin{array}{l}\text { Independent association } \\
\text { of bilirubin level at }\end{array}$ & D-Bil & -1.84 \\
POD 2 and IFSD & I-Bil & $\mathrm{P}<0.0001$ \\
& & 0.33 \\
& & $\mathrm{P}=0.080$ \\
\hline
\end{tabular}

Multivariate linear regression analysis was performed using D-Bil, I-Bil, age, ASA-PS, operation category, and emergency operation as dependent variables, and mortality as the independent variable. IFSD: ICU-free survival days at 28 days after the operation, POD: postoperative day(s), D-Bil: direct bilirubin, I-Bil: indirect bilirubin, ASAPS: American Society of Anesthesiologists-physical status.

ability of D-Bil, on day 7 after admission, to predict a poor outcome was superior to that of I-Bil. Although our findings were consistent with previous studies, this was the first analysis conducted in critically ill postoperative patients to assess the associations between early increases in D-Bil and I-Bil levels during the ICU stay and outcome.

\section{Implications}

Hyperbilirubinemia, or jaundice, is commonly seen in the ICU, with incidence rates of up to $40 \%$ among critically ill patients [10]. A higher total bilirubin level is associated with greater severity of illness, and therefore also with poorer outcomes. Bilirubin is the breakdown product of hemoglobin [11]. Within hepatocytes, I-Bil becomes D-Bil and flows into the bile across the hepatocyte canalicular membrane. Thus, elevation of I-Bil is related to various conditions, including hemolysis and blood transfusion reaction [11]. In the present study, increased I-Bil was common, with a rate of $59.2 \%$ at POD 1 . However, even a moderate increase in I-Bil was not independently associated with postoperative mortality. Furthermore, I-Bil at POD 1 was independently associated with increased IFSD. As this was a retrospective observational study, we could not assess causality. Therefore, our findings regarding the association of I-Bil with IFSD do not imply a protective role of I-Bil. Indeed, I-Bil should be considered as the more toxic form of bilirubin [12], and less protective than D-Bil [13]. As the main focus of the present study was to compare the associations of postoperative I-Bil and D-Bil levels with the clinical outcome, we were not able to assess the etiologies of increased I-Bil in detail. Further studies are necessary to confirm or refute our findings regarding the association between the postoperative I-Bil level and outcome.

Postoperative hepatic dysfunction or bile duct occlusion may be one reason for an elevated D-Bil level. In the present study, even a mild increase in D-Bil at POD 1 was independently associated with a poorer outcome. As mentioned above, our findings do not imply a harmful role of D-Bil. Kim et al. [13] reported that bilirubin nanoparticles consisting of polyethylene glycol-conjugated bilirubin protected against hepatic ischemiareperfusion injury in the liver by preventing oxidative stress. Our findings suggest that for prediction of poor outcomes in postoperative critically ill patients, D-Bil may have higher predictive capability than I-Bil, as shown by previous studies done in various settings, and including neonates [14] and acute liver disease [15,16], cardiac transplantation [17], stroke [5], and sepsis patients [4].

\section{Strengths and limitations}

This is the first study to assess the associations between D-Bil and I-Bil levels and the clinical outcome in critically ill postoperative patients. However, our study had several limitations. First, it used a retrospective design and was therefore potentially subject to systematic error and bias. However, D-Bil and I-Bil levels can be measured objectively and stored electronically at the time of collection, and are also verifiable. Furthermore, the outcome was robust (death) and unlikely to have been entered incorrectly. Second, the study was conducted in one center and the results may not be generalizable. Third, as the mortality was low, the study may have been underpowered. However, we determined the number of patients required using a power calculation, and therefore the risk of type I error was low. Finally, we could not obtain information on the patients' demographics. These characteristics are likely to modulate the predictive capability of bilirubin indices and future studies should focus on their associations. Nonetheless, it is important to note that we focused on a relative comparison between D-Bil and I-Bil levels, rather than on their absolute impact on the outcome.

The present study indicated that the D-Bil level has a more robust association with poor outcome (increased postoperative mortality and decreased IFSD compared with the I-Bil level. Future studies are required to refute or confirm our findings.

\section{ORCID}

Masaharu Nagae, https://orcid.org/0000-0001-7373-2470

Moritoki Egi, https://orcid.org/0000-0002-0099-3060

Kenta Kubota, https://orcid.org/0000-0003-3823-5481

Shohei Makino, https://orcid.org/0000-0001-5495-0288

Satoshi Mizobuchi, https://orcid.org/0000-0003-2059-3272 


\section{References}

1. Kramer L, Jordan B, Druml W, Bauer P, Metnitz PG. Incidence and prognosis of early hepatic dysfunction in critically ill patients--a prospective multicenter study. Crit Care Med 2007; 35: 1099-104.

2. Lescot T, Karvellas C, Beaussier M, Magder S. Acquired liver injury in the intensive care unit. Anesthesiology 2012; 117: 898-904.

3. Limdi JK, Hyde GM. Evaluation of abnormal liver function tests. Postgrad Med J 2003; 79: 307-12.

4. Wu Y, Ren J, Wang G, Gu G, Zhou B, Ding C, et al. Direct bilirubin as a prognostic biomarker in enteric fistula patients complicated with sepsis: a case-control study. Int J Clin Exp Med 2014; 7: 5134-45.

5. Pineda S, Bang OY, Saver JL, Starkman S, Yun SW, Liebeskind DS, et al. Association of serum bilirubin with ischemic stroke outcomes. J Stroke Cerebrovasc Dis 2008; 17: 147-52.

6. Kellum JA, Lameire N. Diagnosis, evaluation, and management of acute kidney injury: a KDIGO summary (Part 1). Crit Care 2013; 17: 204.

7. ARDS Definition Task Force, Ranieri VM, Rubenfeld GD, Thompson BT, Ferguson ND, Caldwell E, et al. Acute respiratory distress syndrome: the Berlin definition. JAMA 2012; 307: 2526-33.

8. European Delirium Association, American Delirium Society. The DSM-5 criteria, level of arousal and delirium diagnosis: inclusiveness is safer. BMC Med 2014; 12: 141.

9. Egi M, Bellomo R, Stachowski E, French CJ, Hart GK, Taori G, et al. Hypoglycemia and outcome in critically ill patients. Mayo Clin Proc 2010; 85: 217-24.

10. Bansal V, Schuchert VD. Jaundice in the intensive care unit. Surg Clin North Am 2006; 86: 1495-502.

11. Scharte M, Fink MP. Red blood cell physiology in critical illness. Crit Care Med 2003; 31(12 Suppl): S651-7.

12. Jenniskens M, Langouche L, Vanwijngaerden YM, Mesotten D, Van den Berghe G. Cholestatic liver (dys)function during sepsis and other critical illnesses. Intensive Care Med 2016; 42: 16-27.

13. Kim JY, Lee DY, Kang S, Miao W, Kim H, Lee Y, et al. Bilirubin nanoparticle preconditioning protects against hepatic ischemia-reperfusion injury. Biomaterials 2017; 133: 1-10.

14. Mamtani M, Patel A, Renge R, Kulkarni H. Prognostic value of direct bilirubin in neonatal hyperbilirubinemia. Indian J Pediatr 2007; 74: 819-22.

15. Shiomi S, Habu D, Kuroki T, Ishida S, Tatsumi N. Clinical usefulness of conjugated bilirubin levels in patients with acute liver diseases. J Gastroenterol 1999; 34: 88-93.

16. Li B, Wang Z, Fang JJ, Xu CY, Chen WX. Evaluation of prognostic markers in severe drug-induced liver disease. World J Gastroenterol 2007; 13: 628-32.

17. Reinhartz O, Farrar DJ, Hershon JH, Avery GJ Jr, Haeusslein EA, Hill JD. Importance of preoperative liver function as a predictor of survival in patients supported with Thoratec ventricular assist devices as a bridge to transplantation. J Thorac Cardiovasc Surg 1998; 116: 633-40. 